\title{
Magnetic and Thermal Properties of $\mathrm{Fe}_{73.5} \mathrm{Si}_{13.5} \mathrm{~B}_{9} \mathrm{Cu}_{1} \mathrm{Nb}_{3}$ Amorphous Ribbon and Ball-Milled Powders
}

\author{
Shih Fan Chen ${ }^{1}$, Shih Hang Huang ${ }^{1}$, Shea Jue Wang ${ }^{1}$, Shih Hsun Chen ${ }^{2, *}$, and Chien Chon \\ Chen $^{2}$ \\ ${ }^{1}$ Institute of Materials Science and Engineering, National Taipei University of Technology, Taipei 10608, \\ Taiwan; ${ }^{2}$ Department of Energy Engineering, National United University, 1, Lienda, Miaoli 36003, Taiwan.
}

Received: October 11, 2014 / Accepted: October 28, 2014

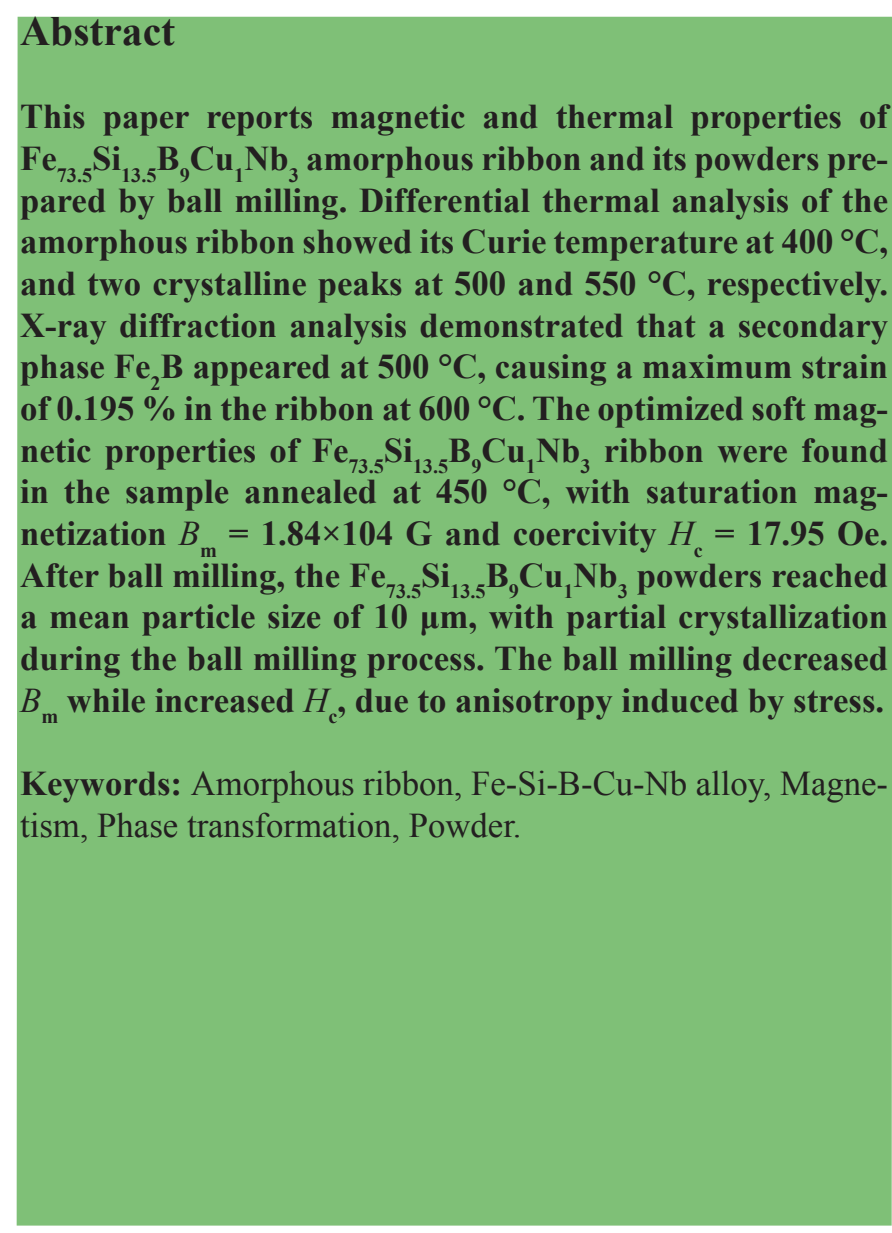

${ }^{*}$ Corresponding author: brucechen.mse90g@gmail.com

\section{Introduction}

The excellent soft magnetic properties of amorphous ribbons have been widely developed since late 1980's (Otsuka et al., 2009). It is known that Iron-based amorphous alloys have high tenacity and strength, good corrosion resistance, and can be made as thin ribbons while at a low cost. Silicon steel sheets are the earliest applications of such soft magnetic materials (Akhter al., 2009), and their soft magnetic properties could be enhanced by annealing the ribbon in vacuum under magnetic saturation (Muhammad et al., 2014), allowing applications in cores for electrical equipment such as transformers or pulse power devices (Francoeur et al., 2012).

In order to retain the excellent magnetic and mechanical properties, these materials are usually restricted to low dimensions, such as ribbons, wires or powders. However, the working parts in devices usually require specific shapes. However, the functions of amorphous alloys are significantly influenced by shapes of sheets, wires, powders or films, because of their glass forming ability (Yoshida et al., 2000). The amorphous alloys can be fabricated by conventional casting but limited to the mold shape. Because the coercively of these amorphous alloys is lower than other types of oxide magnetic materials, many efforts are still being devoted to obtain amorphous alloy cores with desired shapes for applications in high-frequency range. The amorphous alloys offer excellent properties in coercively, but it is difficult make them into certain sharps.

Powder metallurgy provides a prospective solution to make compact products based on low-dimensional resources, enabling practical applications of metallic amorphous alloys. For this reason, how to prepare amorphous alloy powders for 
the pressure molding process becomes a main research topic (Zaluska et al. 1983; Makino et al., 2009; Perigo et al., 2011; Makino, 2012; Olekšáková et al, 2013; Li et al., 2012; Inoue et al., 2001). In this study, $\mathrm{Fe}_{73.5} \mathrm{Si}_{13.5} \mathrm{~B}_{9} \mathrm{Cu}_{1} \mathrm{Nb}_{3}$ powders were prepared by a ball milling process, and their thermal and magnetic properties were investigated to optimize the process.

\section{Experimental Procedures}

In this research, the experimental $\mathrm{Fe}_{73.5} \mathrm{Si}_{13.5} \mathrm{~B}_{9} \mathrm{Cu}_{1} \mathrm{Nb}_{3}$ Finement ribbons were provided by Hitachi Corp. The powders were prepared from ribbons by the ball milling process. Because finer particles could improve the electric property, decrease the core loss and raise the coercivity (Hsieh et al., 2009), a two-step milling process was used to check the milling effect.

The $\mathrm{Fe}_{73.5} \mathrm{Si}_{13.5} \mathrm{~B}_{9} \mathrm{Cu}_{1} \mathrm{Nb}_{3}$ ribbons were annealing at 400, 450, $500,550,600,650$ and $700^{\circ} \mathrm{C}$ for 15 minutes, respectively, in a vacuum to investigate their thermal effects on magnetic properties. To prepare for the ball milling, the ribbons were firstly cut into approximately square flakes and then crushed to smaller debris by a crushing machine. Two-step milling at 250 and $300 \mathrm{rpm}$ for 24 and 20 hours, respectively, were sequentially preceded. For the second milling, a higher milling speed was required to produce finer powders. Finally, the smaller milling balls were used to separate the agglomerates generated from the second milling. All milling processes were done under air atmosphere.

The morphology was observed by a Scanning Electron Microscope (SEM, Hitachi-S4700), and the average particle size was measured by a particle size distribution analyzer (Horiba La950). The phase transformations after annealing were investigated by X-ray diffraction (XRD, Rigaku DMX-2200). An LCR (L: inductance; C: capacitance; R: resistance) Meter (Agilent E4980A) was utilized to measure the permeability and quality factor at different frequency. A Vibrating Sample Magnetometer (VSM, LakeShore 7400) was used to examine the magnetic properties of ribbon or powders.

\section{Results and Discussion}

Figure 1 shows XRD patterns of the $\mathrm{Fe}_{73.5} \mathrm{Si}_{13.5} \mathrm{~B}_{9} \mathrm{Cu}_{1} \mathrm{Nb}_{3}$ ribbons after annealing at different temperatures. It is found that an $\alpha-\mathrm{Fe}(\mathrm{Si})$ phase appears clearly without any other phase annealed at $450{ }^{\circ} \mathrm{C}$. At a higher temperature, an $\mathrm{Fe}_{2} \mathrm{~B}$ phase appears at $500{ }^{\circ} \mathrm{C}$. The peaks of $\alpha-\mathrm{Fe}(\mathrm{Si})$ and $\mathrm{Fe}_{2} \mathrm{~B}$ become evident when the annealing temperature is raised over $500{ }^{\circ} \mathrm{C}$. Similar phenomenon was observed during the crystallization of Fe-B-Si system via a two-step process (Inoue, 2001; Akhter et al., 2009). The strain in the ribbon can be inferred through Williamson-Hall equation. Firstly, the average grain size $D$ can be determined from the XRD pattern using Scherrer relationship:

$$
D=\frac{0.9 \lambda}{\beta \cos \theta},
$$

where $\lambda$ is the X-ray wavelength, $\theta$ is the angle of diffraction, and $\beta$ (rad) is the full width at half maximum (FWHM) of the diffraction peak. Then, the Williamson-Hall equation can be modified from the eq. (1) as follow:

$$
(\beta \cos \theta / \lambda)^{2}=(0.9 / D)^{2}+16 \varepsilon^{2}(\sin \theta / \lambda)^{2} .
$$

Here, $\varepsilon$ is the strain in the sample. The strains measured from the experimental samples are shown in Fig. 2. The strain rises after $450{ }^{\circ} \mathrm{C}$ because of the $\mathrm{Fe}_{2} \mathrm{~B}$ precipitation. The maximum strain reaches $0.195 \%$ at $600{ }^{\circ} \mathrm{C}$, and it then decrease after 600 ${ }^{\circ} \mathrm{C}$. The internal strain can be ascribed to grain size and the secondary phase precipitates.

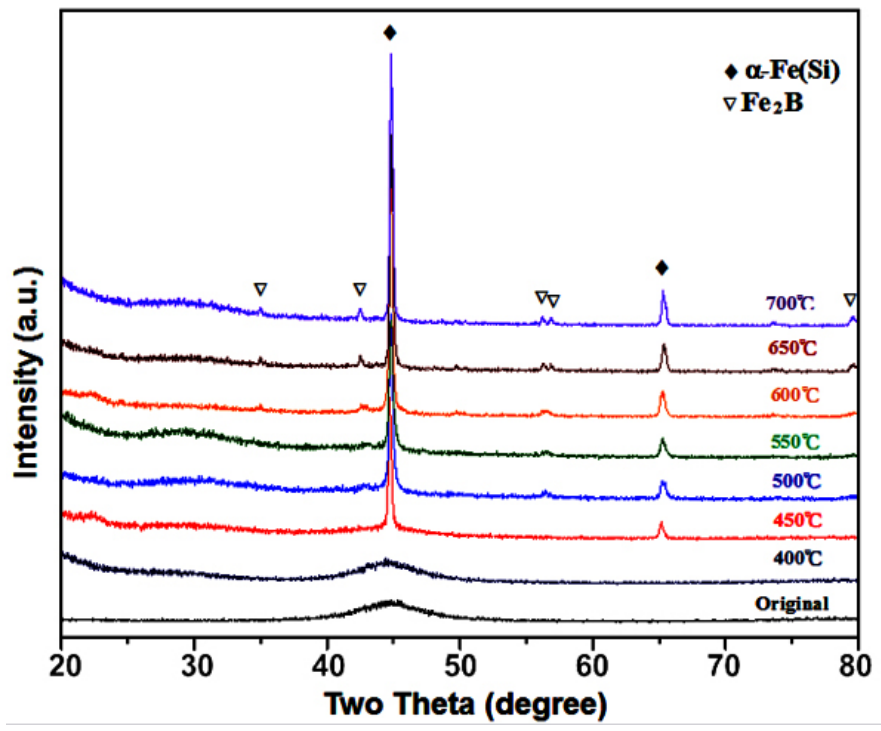

Figure 1. XRD patterns of $\mathrm{Fe}_{73.5} \mathrm{Si}_{13.5} \mathrm{~B}_{9} \mathrm{Cu}_{1} \mathrm{Nb}_{3}$ original ribbon and ribbons annealed at $400-700{ }^{\circ} \mathrm{C}$ for $15 \mathrm{~min}$.

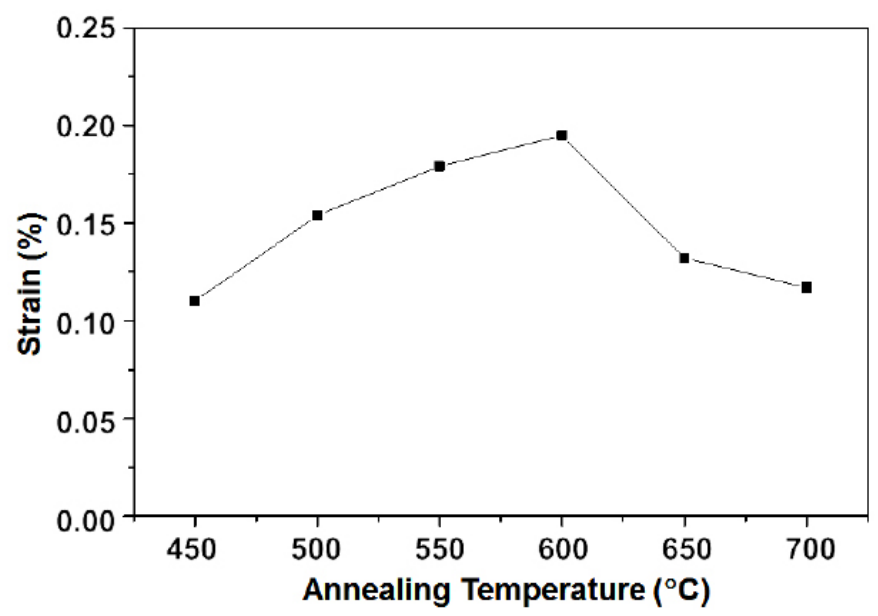

Figure 2. Strain dependence of annealing temperature in $\mathrm{Fe}_{73.5} \mathrm{Si}_{13.5} \mathrm{~B}_{9} \mathrm{Cu}_{1} \mathrm{Nb}_{3}$ ribbon.

Figure 3 is the SEM image of a quenched $\mathrm{Fe}_{73.5} \mathrm{Si}_{13.5} \mathrm{~B}_{9} \mathrm{Cu}_{1} \mathrm{Nb}_{3}$ ribbon after annealing at $550{ }^{\circ} \mathrm{C}$ for $15 \mathrm{~min}$. Dendrite structure is observed in the ribbon matrix, which is a typical precipitate microstructure of $\alpha$-Fe (Zaluska et al., 1983). This observation is consistent with the XRD result.

Figure 4 shows differential thermal analysis (DTA) result of the $\mathrm{Fe}_{73.5} \mathrm{Si}_{13.5} \mathrm{~B}_{9} \mathrm{Cu}_{1} \mathrm{Nb}_{3}$ ribbons in argon atmosphere at a heating rate of $20^{\circ} \mathrm{C} / \mathrm{min}$. The Curie temperature is determined as $400{ }^{\circ} \mathrm{C}$. Two crystalline peaks appear at 500 and $550{ }^{\circ} \mathrm{C}$, respectively. Comparing with the XRD results, these two peaks represent the crystallization of $\alpha-\mathrm{Fe}(\mathrm{Si})$ and $\mathrm{Fe}_{2} \mathrm{~B}$ phases, sequentially. 


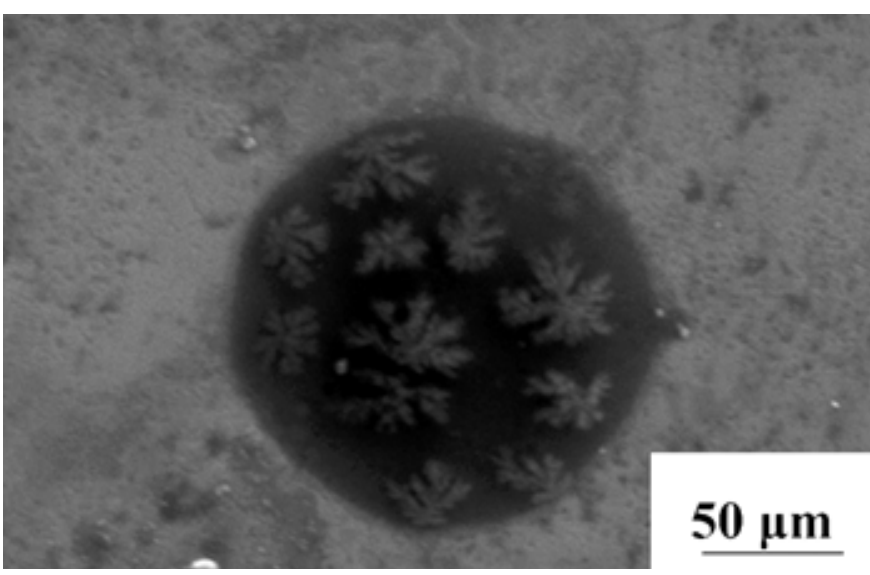

Figure 3. SEM image of $\mathrm{Fe}_{73.5} \mathrm{Si}_{13.5} \mathrm{~B}_{9} \mathrm{Cu}_{1} \mathrm{Nb}_{3}$ alloy ribbon annealed at $550{ }^{\circ} \mathrm{C}$ for $15 \mathrm{~min}$.

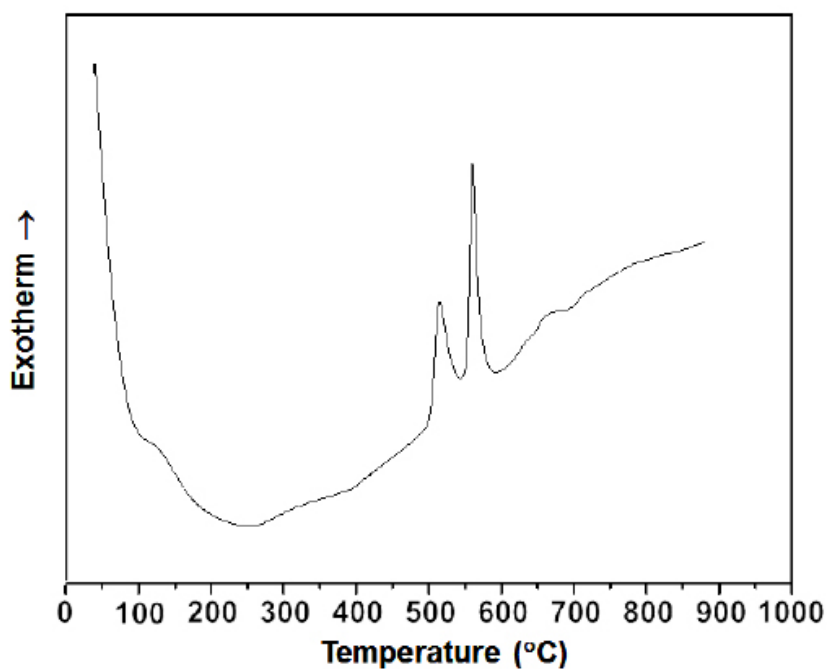

Figure 4. DTA curve of $\mathrm{Fe}_{73.5} \mathrm{Si}_{13.5} \mathrm{~B}_{9} \mathrm{Cu}_{1} \mathrm{Nb}_{3}$ ribbon at a heating rate of $20^{\circ} \mathrm{C} / \mathrm{min}$.

The saturation magnetization $B_{\mathrm{m}}$ and coercivity $H_{\mathrm{c}}$ of ribbon are measured by using the VSM. Figure 5 shows the saturation magnetization and coercivity dependence of the annealing temperature. The $H_{\mathrm{c}}$ increases after annealing because of the raise of magneto-crystalline anisotropy if the grains are all over 10 $\mathrm{nm}$ (Herzer et al., 1997), and the $B_{\mathrm{m}}$ is relevant to the amount of $\alpha-\mathrm{Fe}(\mathrm{Si})$ and $\mathrm{Fe}_{2} \mathrm{~B}$ grain size (Tingdong et al., 2006). From Fig. 5 , the maximum $B_{\mathrm{m}}$ is around $1.84 \times 10^{4} \mathrm{G}$ at $450{ }^{\circ} \mathrm{C}$, when only $\alpha-\mathrm{Fe}(\mathrm{Si})$ phase appears. The $B_{\mathrm{m}}$ begins to decrease until a minimum $1.6 \times 10^{4} \mathrm{G}$ at $600{ }^{\circ} \mathrm{C}$, due to the increased strain after 450 ${ }^{\circ} \mathrm{C}$. The $B$ rises again after $600{ }^{\circ} \mathrm{C}$, because of the decreased strain (Fig. 2). The formation of $\mathrm{Fe}_{2} \mathrm{~B}$ phase and grain coarsening deteriorate the saturation magnetization at $700{ }^{\circ} \mathrm{C}$. A soft magnetic material requires high magnetization $B_{\mathrm{m}}$ but low $H_{\mathrm{c}}$. To reach these requirements, the optimized soft magnetic properties of $\mathrm{Fe}_{73.5} \mathrm{Si}_{13.5} \mathrm{~B}_{9} \mathrm{Cu}_{1} \mathrm{Nb}_{3}$ ribbon are therefore $B_{\mathrm{m}}=1.84 \times 10^{4}$ $\mathrm{G}$ and $H_{\mathrm{c}}=17.95 \mathrm{Oe}$ after annealing at $450^{\circ} \mathrm{C}$.

Powders are prepared by ball milling of the ribbon. The obtained particles have irregular shpaes, as shown in the SEM images in Fig. 6. The particle sizes are statistically measured, as plotted in Fig. 7. The particle mean size is about $80 \mu \mathrm{m}$ after

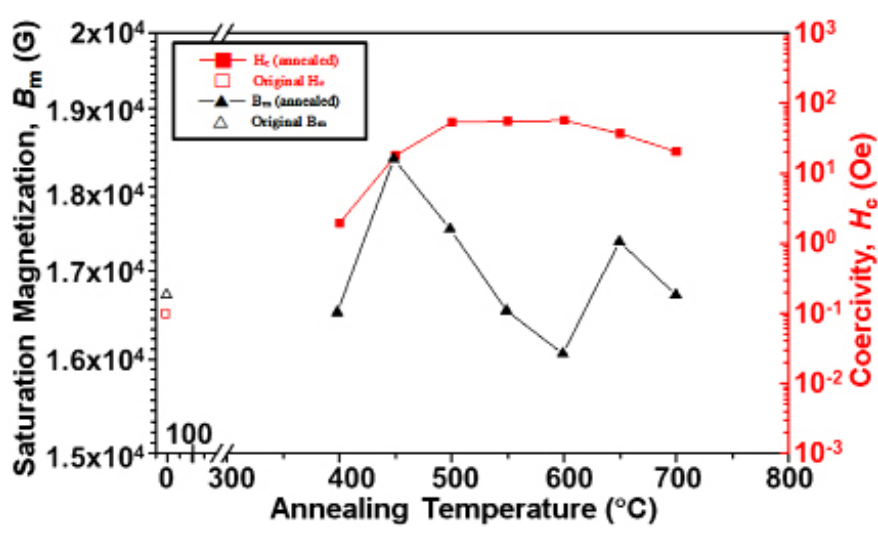

Figure 5. Saturation magnetization $B_{\mathrm{m}}$ and coercivity $H_{\mathrm{c}}$ dependence of annealing temperature of $\mathrm{Fe}_{73.5} \mathrm{Si}_{13.5} \mathrm{~B}_{9} \mathrm{Cu}_{1} \mathrm{Nb}_{3}$ ribbon.

the first milling, and which is reduced to about $10 \mu \mathrm{m}$ after the second milling.

In order to examine the milling effect on the $\mathrm{Fe}_{73.5} \mathrm{Si}_{13.5} \mathrm{~B}_{9} \mathrm{Cu}_{1} \mathrm{Nb}_{3}$ powders, XRD is utilized to check their phase structure. Besides to the original alloy ribbon, a ribbon annealed at $300^{\circ} \mathrm{C}$ for 1 hour is also used for ball milling. Generally, an amorphous alloy does not crystallize below the crystallization temperature. Figure 8 shows the XRD patterns of powders from the original and annealed ribbons. Only $\alpha-\mathrm{Fe}(\mathrm{Si})$ peaks are observed, and its FWHM decreases as the milling time increases. Comparing to the XRD patterns of annealed ribbons in Fig. 1, it is found that the ball milling process yields an effect similar to annealing at $400{ }^{\circ} \mathrm{C}$. It is because that the abraded balls and capacity of steel provide nucleation sites for the $\alpha$-Fe and iron-rich areas. Milling process also introduces high energy to the powders. Even after a short period of milling time, a small fraction of the powders could have enough iron concentration and activation energy to undergo crystallization (Bansal et al., 1994; Nowosielski et al., 2007). This crystallization mode is different from thermal crystallization. The thermal crystallization involves the primary crystallization $(\alpha-\mathrm{Fe}(\mathrm{Si}))$, and the eutectic crystallization $\left(\mathrm{Fe}_{2} \mathrm{~B}\right)$ is similar to the crystallization induced by milling under an argon atmosphere. Only primary crystallization would occur under air atmosphere (Zhang et al., 2008). There are other reasons for the partial crystallization. For example, the composition may change due to abrasion resulted by steel milling balls or container, and the milling may induce defects as preferred sites for nanocrystal precipitation (Bednarčík et al., 2004).

Figure 9 shows the VSM analysis of origin ribbons and powders. The easy axis of the induced anisotropy is transversal magnetic anisotropy. The curves of ribbons are of a low coercivity of 0.01 Oe and a high saturation magnetization of $1.67 \times 10^{4} \mathrm{G}$. After milling, the susceptibility of the linear magnetization curve decreases, which means that internal stress increases (Hofmann et al., 1996). The $H_{c}$ rises to 30 Oe after the second milling, but the $H_{c}$ merely goes up to 0.41 Oe after annealing without milling. The induced anisotropy may be the major reason causing increased $H_{\mathrm{c}}$ but no difference between the first and second milling. 

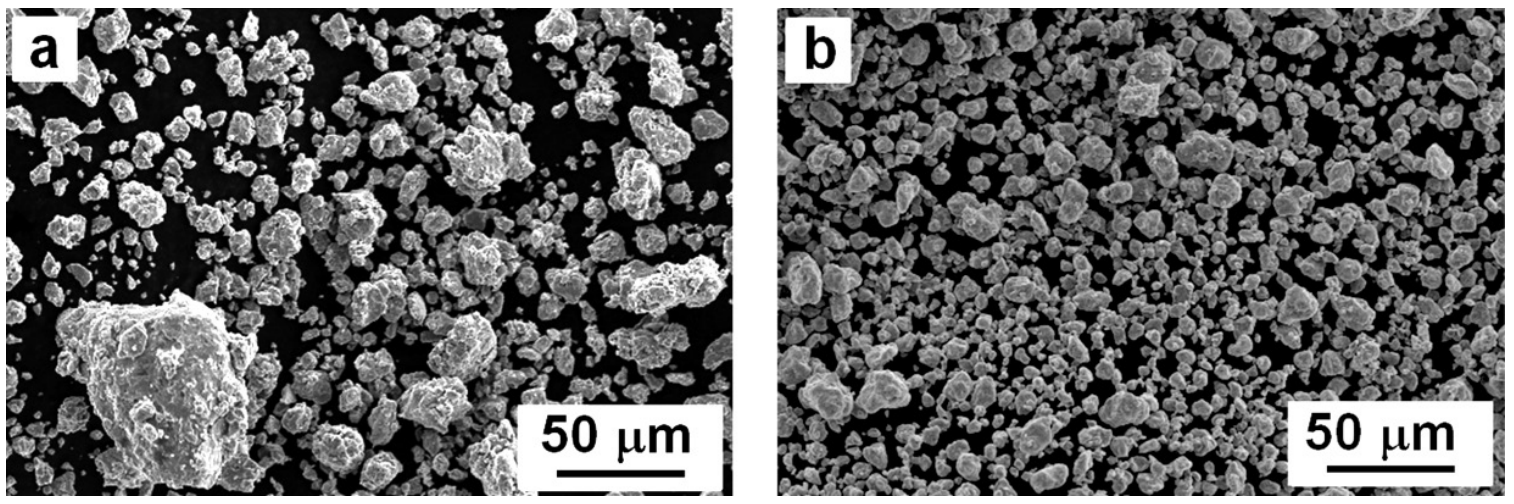

Figure 6. SEM images of $\mathrm{Fe}_{73.5} \mathrm{Si}_{13.5} \mathrm{~B}_{9} \mathrm{Cu}_{1} \mathrm{Nb}_{3}$ particles after 1st (a) and 2nd (b) ball milling.

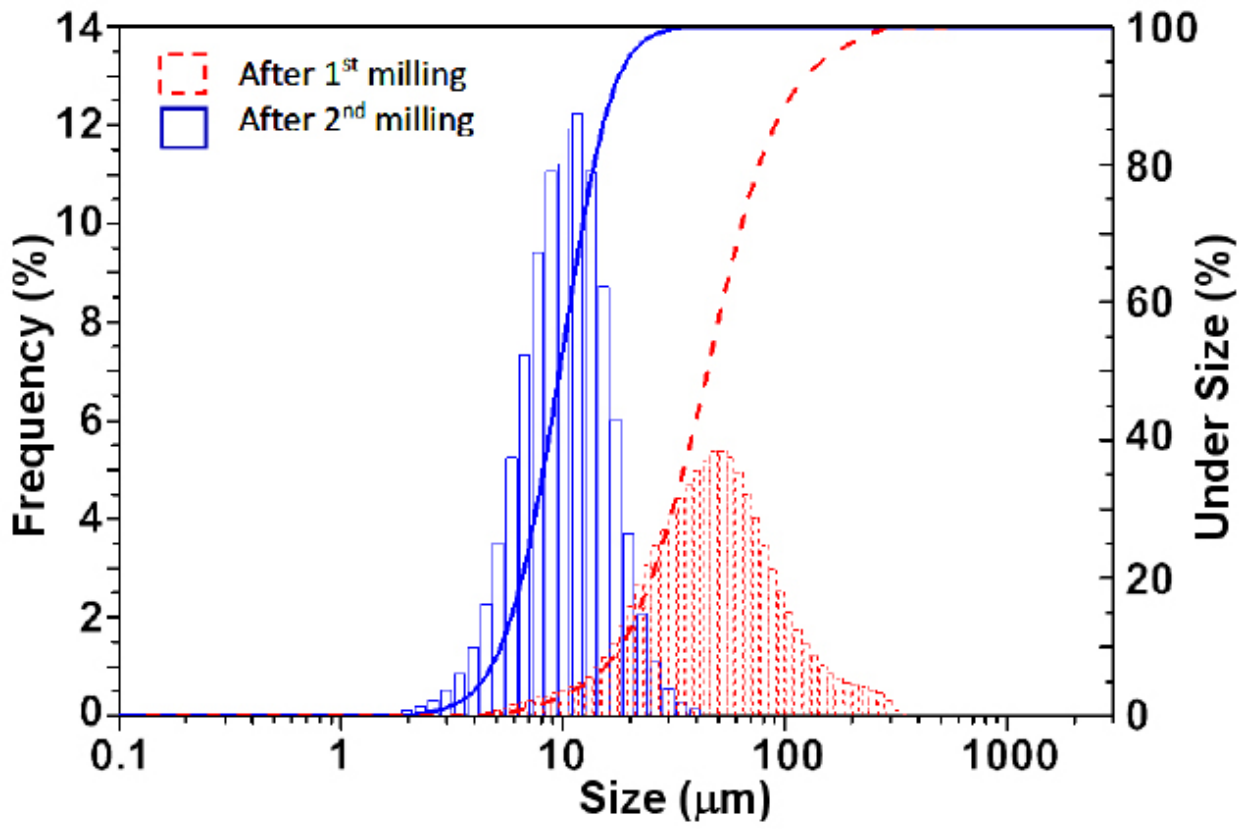

Figure 7. Particle size distributions of $\mathrm{Fe}_{73.5} \mathrm{Si}_{13.5} \mathrm{~B}_{9} \mathrm{Cu}_{1} \mathrm{Nb}_{3}$ powders after the 1st and 2nd milling.

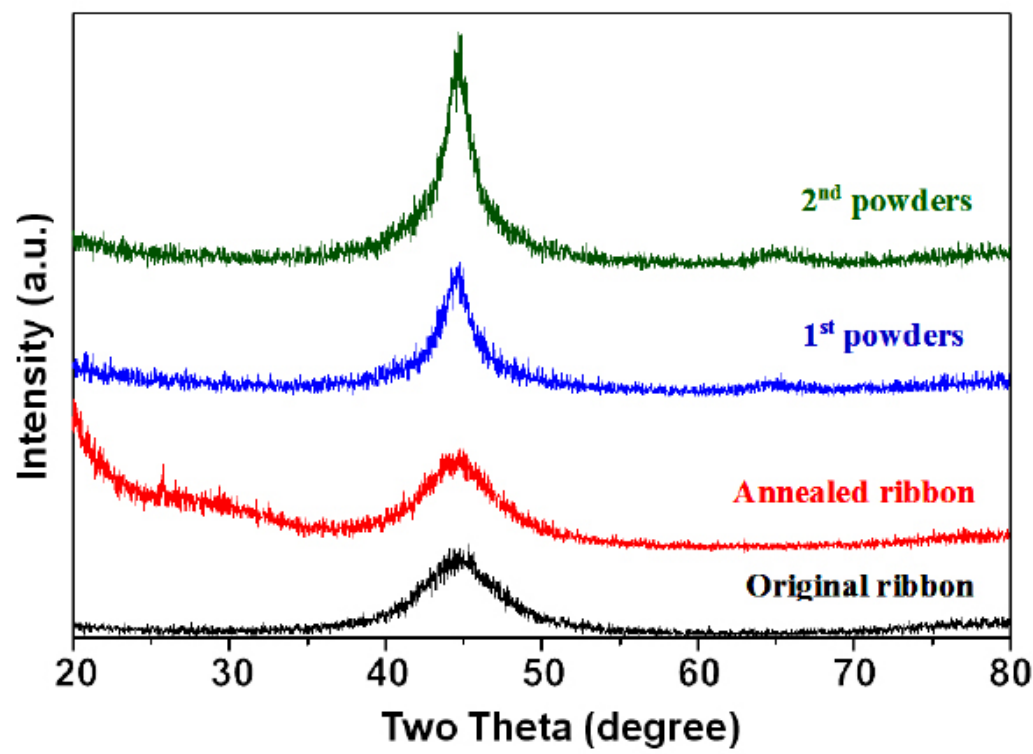

Figure 8. XRD patterns of the original and annealed ribbons, and 1st and 2nd milled powders made from the ribbon annealed at $300{ }^{\circ} \mathrm{C}$ for 1 hour. 


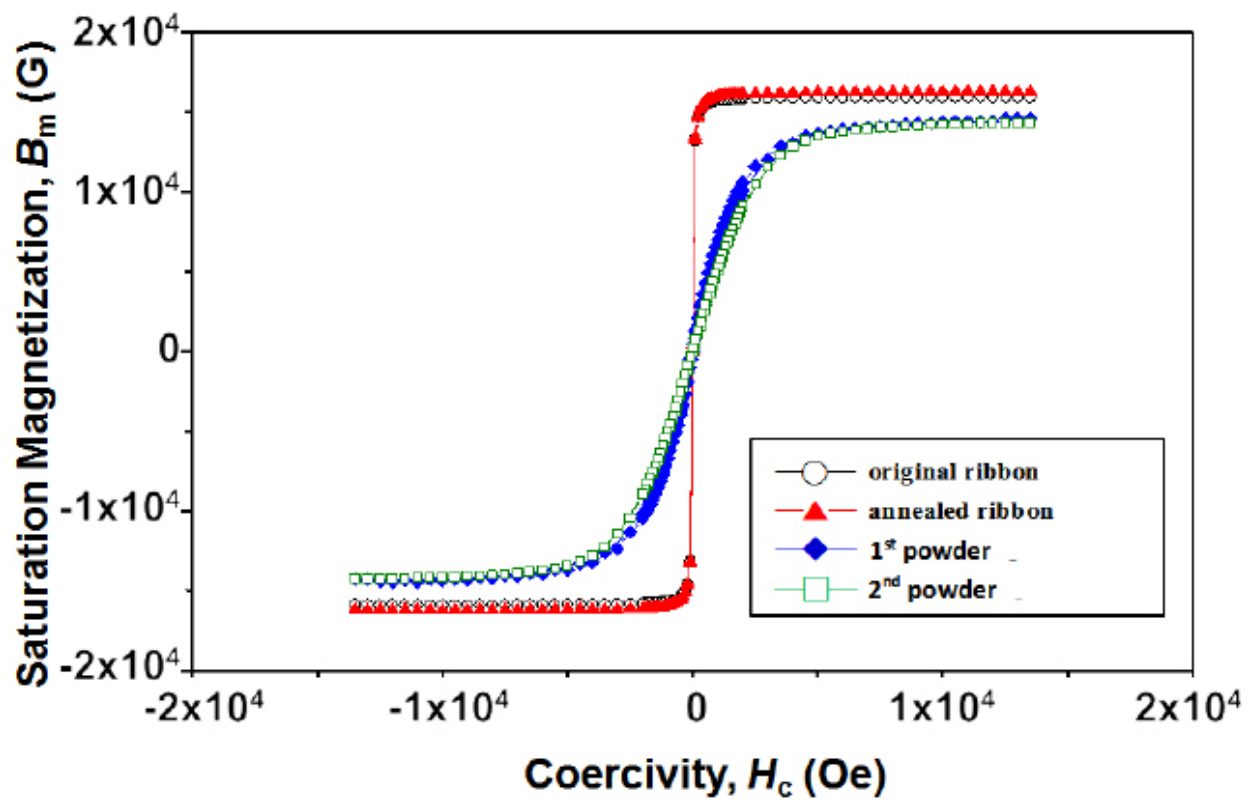

Figure 9. Saturation magnetization $B_{\mathrm{m}}$ dependence of coercivity $H_{\mathrm{c}}$ hysteresis loops of the original and ribbon annealed at $300^{\circ} \mathrm{C}$, and 1 st and 2 nd milled powders made from the annealed ribbon.

\section{Conclusions}

The thermalandmagnetic propertiesofthe $\mathrm{Fe}_{73.5} \mathrm{Si}_{13.5} \mathrm{~B}_{9} \mathrm{Cu}_{1} \mathrm{Nb}_{3}$ amorphous ribbon and ball-milled powders were investigated. From the amorphous ribbon, the Curie temperature was determined as $400{ }^{\circ} \mathrm{C}$, and two crystallization temperatures were observed at 500 and $550{ }^{\circ} \mathrm{C}$ for $\alpha-\mathrm{Fe}(\mathrm{Si})$ and $\mathrm{Fe}_{2} \mathrm{~B}$, respectively. The maximum strain was inferred to be $0.195 \%$ in the ribbon annealed at $600{ }^{\circ} \mathrm{C}$. The optimized soft magnetic properties of $\mathrm{Fe}_{73.5} \mathrm{Si}_{13.5} \mathrm{~B}_{9} \mathrm{Cu}_{1} \mathrm{Nb}_{3}$ ribbons were found to be $B_{\mathrm{m}}=1.84 \times 10^{4} \mathrm{G}$ and $H_{\mathrm{c}}=17.95 \mathrm{Oe}$ after annealing at $450{ }^{\circ} \mathrm{C}$. After ball milling, the $\mathrm{Fe}_{735} \mathrm{Si}_{135} \mathrm{~B}_{9} \mathrm{Cu}_{1} \mathrm{Nb}_{3}$ powders reached a mean size of $10 \mu \mathrm{m}$, with partial crystallization during the milling process. The ball milling decreased the $B_{\mathrm{m}}$ while increased $H_{\mathrm{c}}$ due to the anisotropy induced by stress.

\section{Acknowledgements}

This work was financially supported by the Chung-Shan Institute of Science and Technology (CSIST), Taiwan.

\section{References}

Akhter JI, Iqball M, Siddique M, Ahmad M, Haq MA, Shaikh MA and $\mathrm{Hu}$ ZQ (2009) Crystallization and Hardness of Melt Spun $\mathrm{Fe}_{73} \mathrm{Si}_{13} \mathrm{~B}_{9} \mathrm{Nb}_{4} \mathrm{Cu}_{1}$ Alloy. J Mater Sci Technol 25 (1): 48-52.

Bansal C, Fultz B and Johnson WL (1994) Crystallization of Fe-B-Si metallic glass during ball milling. Nanostruct Mater 4 (8): 919-925.

Bednarčík J, Kováč J, Kollár P, Roth S, Sovák P, Balcerski J, Polanski $\mathrm{K}$ and Švec T (2004) Crystallization of CoFeSiB metallic glass induced by long-time ball milling. J Non-Cryst Solids 337 (1): 42-47.

Francoeur B and Couture P (2012) Continuous-annealing method for producing a flexible, curved, soft magnetic amorphous alloy ribbon. J Appl Phys 111: 07A309 - 07A309-3.

Hofmann B and Kronmüller H (1996) Stress-induced magnetic anisotropy in nanocrystalline $\mathrm{FeCuNbSiB}$ alloy. J Magn Magn Mater 152 (1-2): 91-98.

Herzer G (1997) Nanocrystalline soft magnetic alloys. In: KHJ Buschow (ed.) Handbook of Magnetic Materials. Elsevier Science B.V., pp. 437.

Hsieh TC (2009) Effects of bimodal particle size distribution on the magnetic performance for compressed powder core (Master Thesis). Department of Materials Science and Engineering, National Taiwan University of Science and Technology, Taiwan.

Inoue A (2001) Bulk amorphous and nanocrystalline alloys with high functional properties. Mater Sci Eng A304-306: 1-10.

Li HX, Gao JE, Wang SL, Yi S and Lu ZP (2012) Formation cystallization behavior, and soft magnetic properties of FeCSiBP bulk metallic glasses fabricated using industrial raw materials. Metall Mater Trans A43 (8): 2615-2619.

Makino A, Men H, Kubota T, Yubuta K and Inoue A (2009) FeSiBPCu nanocrystalline soft magnetic alloys with high BS of 1.9 tesla produced by crystallizing hetero-amorphous phase. Mater Trans 50: 204209

Makino A (2012) Nanocrystalline soft magnetic Fe-Si-B-P-Cu alloys with high Bs of 1.8-1.9T contributable to energy saving. IEEE Trans Magn 48 (4): 1331-1335.

Muhammad D, Khan FA, Farabi HM and Alam MJ (2014) Electrical and Magnetic Transport Properties of Nanocrystalline $\mathrm{Fe}_{73.5} \mathrm{Si}_{13.5} \mathrm{~B}_{9} \mathrm{Cu}_{1} \mathrm{Nb}_{3}$ Alloy. J Superconduct Novel Magn 27 (6): 1525-1530.

Nowosielski R (2007) Soft magnetic polymer-metal composites consisting of nanostructural Fe-basic powders. J Achiev Mater Manuf Eng 24 (1): 68-77.

Olekšáková D, Füzer J, Kollár P and Roth S (2013) Components of the core losses under low frequency magnetic field of the bulk ni-fecompacted powder materials. J Magn Magn Mater 333:18-21.

Otsuka I, Kadomura T, Ishiyama K and Yagi M (2009) Magnetic properties of Fe-based amorphous powder cores with high magnetic flux 
density. IEEE Trans Magn 45 (10): 4294-4297.

Perigo EA, Nakahara S, YamadaYP, Hazan YD and Graule T (2011) Magnetic properties of soft magnetic composites prepared with crystalline and amorphous powder. J Magn Magn Mater 323(15):1938-1944.

Tingdong Z, Difei L and Qiang L (2006) Influence of anneal temperature on the structure and magnetic characteristic of $\mathrm{FeCuNbSiB}$ fiber. Rare Metal Mater Eng 12 (35): 1-3.
Yoshida S, Mizushima T, Hatanai T, and Inoue A (2000) Preparation of new amorphous powder cores using Fe-based glassy alloy. IEEE Trans Magn 36 (5): 3424-3429.

Zaluska A and Matyja H (1983) Crystallization characteristics of amorphous Fe-Si-B alloys. J Mater Sci 18: 2163-2172.

Zhang C, Zhang Z, Qi Z, Qi Y, Zhang J and Bian X (2008) Ball milling induced abnormal crystallization behavior of an amorphous $\mathrm{Fe}_{78} \mathrm{~S}$ $\mathrm{i}_{9} \mathrm{~B}_{13}$ alloy. J Non-Cryst Solids 354 (32): 3812-3816. 